\title{
Society for Cardiovascular Magnetic Resonance (SCMR) recommended CMR protocols for scanning patients with active or convalescent phase COVID-19 infection
}

\author{
Sebastian Kelle $\mathrm{e}^{1,2^{*}}$ D, Chiara Bucciarelli-Ducci ${ }^{3}$, Robert M. Judd ${ }^{4}$, Raymond Y. Kwong ${ }^{5}$, Orlando Simonetti ${ }^{6}$, \\ Sven Plein ${ }^{7}$, Francesca Raimondi ${ }^{8}$, Jonathan W. Weinsaft ${ }^{9}$, Timothy C. Wong ${ }^{10}$ and James Carr ${ }^{11}$
}

\begin{abstract}
The aim of this document is to provide specific recommendations on the use of cardiovascular magnetic resonance (CMR) protocols in the era of the COVID-19 pandemic. In patients without COVID-19, standard CMR protocols should be used based on clinical indication as usual. Protocols used in patients who have known / suspected active COVID-19 or post COVID-19 should be performed based on the specific clinical question with an emphasis on cardiac function and myocardial tissue characterization. Short and dedicated protocols are recommended.
\end{abstract}

Keywords: Recommendations, CMR, COVID-19, Protocol, Indication, SCMR, SARS-CoV-2, Cardiac MRI, Pandemic, Heart

\section{Purpose}

Society for Cardiovascular Magnetic Resonance (SCMR) guidance for the practice of cardiovascular magnetic resonance (CMR) during the COVID-19 pandemic have recently been published [1]. The aim of this document is to provide more specific recommendations on the CMR protocols for scanning patients with known or suspected severe acute respiratory syndrome coronavirus 2 (SARS$\mathrm{CoV}-19)$ infection or those recovering from the disease. These recommendations are not meant to be restrictive but rather to serve as a general framework. They also serve as the basis for registries and clinical studies in patients with SARS-CoV-2 infection, to ensure consistency

\footnotetext{
* Correspondence: kelle@dhzb.de

This article is a recommendation of the Society for Cardiovascular Magnetic Resonance (SCMR). Peer review of this article has been carried out within the society.

'DZHK (German Centre for Cardiovascular Research), Berlin, Germany

${ }^{2}$ German Heart Institute Berlin and Charité University Medicine Berlin, Augustenburger Platz 1, 13353 Berlin, Germany

Full list of author information is available at the end of the article
}

between local, national and international efforts. All recommendations will be updated continuously and provided online in the SCMR's coronavirus disease 2019 (COVID-19) Preparedness Toolkit https://scmr.org/ page/COVID19.

\section{Common CMR-indications in patients with COVID-19}

The effects of COVID-19 on cardiac structure, function, and tissue properties are largely uncertain. First reports are indicating potential myocardial injury or involvement in the acute phase of COVID-19 and post infection [2-9]. CMR is the non-invasive imaging method of choice for structural and functional evaluation of the heart and has unique tissue characterization abilities and will therefore play a key role in many patients recovering from COVID19 and cardiac involvement [10-12]. Adults and children appear to have different presentations with some reports of children being affected by a hyperinflammatory syndrome with acute myocarditis or Kawasaki-like clinical 
presentation [13, 14]. Based on recent literature, the following are the most likely indications for CMR in patients with active or convalescent phase of COVID-19:

\section{Expected CMR-indications in patients within active or convalescent phase of COVID-19}

Adults:

- Left- and right ventricular dysfunction (heart failure)

- Myocarditis (including systemic inflammatory disease, cardiotoxicity)

- Pericarditis

- Myocardial infarction with non-obstructive coronary arteries (MINOCA)

- Chest pain (chronic coronary syndrome)

- Acute myocardial infarction

- Stress induced cardiomyopathy (Takotsubo)

- Ventricular arrythmia, resuscitated cardiac arrest

- Pulmonary hypertension

- Vasculitis

Children

- Left- and/or right ventricular dysfunction (heart failure)

- Hyperinflammatory syndrome or Kawasaki-like features

- Acute vasculitis

- Cardiogenic shock

\section{CMR protocols}

In many clinical scenarios, CMR protocols in the context of COVID-19 infection will need to be short and adapted to the breath-hold ability of patients. Short protocols also help to minimize exposure risks for healthcare personal and patients (Table). Whenever possible, CMR studies should be postponed until patients are no longer contagious so as to avoid exposure to scan personnel. Recently, specific recommendations how to perform CMR in the current COVID-19 pandemic have been published by the SCMR [1] and European Association of Cardiovascular Imaging (EACVI) [15]. Acquisition and reporting should follow general SCMR guidance $[16,17]$. If contrast administration is planned, check of kidney function is recommended in COVID-19 patients, however not mandatory particularly with appropriate (macrocyclic) contrast agents. Wherever possible, a COVID-19 dedicated CMR scanner should be used for scanning patients with active infection.

\section{Recommended CMR-protocols in adult patients with active/post COVID-19}

\begin{tabular}{ll}
\hline Recommended CMR-sequences & $\begin{array}{l}\text { Answering most clinical } \\
\text { questions } \\
\text { Minimum }\end{array}$ \\
Survey & $\begin{array}{l}\text { Minimum } \\
\text { Cine sequences } \\
\text { (SAx full coverage, LAX: 4Ch; 2Ch; }\end{array}$ \\
3Ch) & \\
T2- weighted sequences (STIR) & Desirable \\
(myocardium/pericardium) & \\
Parametric Mapping & Desirable \\
(T1-native, T2, T1-post (calculate & \\
ECV) &
\end{tabular}

Recommended CMR-protocols in adult patients with active/post COVID-19 (Continued)

$\begin{array}{ll}\begin{array}{l}\text { Acquisition based myocardial strain } \\ \text { (Tagging, DENSE, fSENC) }\end{array} & \text { Optional } \\ \text { Stress perfusion (vasodilator) } & \text { Optional } \\ \text { Late gadolinium enhancement } & \text { Minimum (SAx) } \\ \text { (LGE) } & \text { Desirable (long axis) } \\ \text { 2D-flow (aorta \& pulmonary arteries) } & \text { Desirable } \\ \text { 4D-flow } & \text { Optional } \\ \text { Angiography (pulmonary vessels) } & \text { Optional } \\ \text { Lung imaging } & \text { Optional }\end{array}$

$2 \mathrm{Ch}=$ two chamber; $3 \mathrm{Ch}=$ three chamber; $4 \mathrm{Ch}=$ four chamber; DENSE = displacement encoding with stimulated echoes; ECV = extracellular volume fraction; $\mathrm{LGE}=$ late gadolinium enhancement; $\mathrm{SAx}=$ short axis; SENC = strain encoding; STIR = short tau inversion recovery

Recommended CMR-protocols in children with active/post COVID-19

\begin{tabular}{|c|c|}
\hline Recommended CMR-sequences & $\begin{array}{l}\text { Answering most } \\
\text { clinical questions }\end{array}$ \\
\hline Survey & Minimum \\
\hline $\begin{array}{l}\text { Cine sequences } \\
\text { (SAX full coverage, LAX: 4-CH; } 2-C H ; 3-C H)\end{array}$ & Minimum \\
\hline $\begin{array}{l}\text { T2- weighted sequences (STIR) } \\
\text { (myocardium/pericardium) }\end{array}$ & Minimum \\
\hline $\begin{array}{l}\text { Parametric Mapping } \\
\text { (T1-native, T2, T1-post (calculate ECV) }\end{array}$ & Desirable \\
\hline $\begin{array}{l}\text { Acquisition based myocardial strain } \\
\text { (Tagging, DENSE, fSENC) }\end{array}$ & Desirable \\
\hline Late gadolinium enhancement (LGE) & $\begin{array}{l}\text { Minimum (SAX) } \\
\text { Desirable (long axis) }\end{array}$ \\
\hline 2D-flow (aorta \& pulmonary arteries) & Desirable \\
\hline 4D-flow & Optional \\
\hline Angiography (pulmonary vessels) & Optional \\
\hline 3D sequence for coronary artery anatomy & Desirable \\
\hline $\begin{array}{l}\text { Lung imaging } \\
\text { (T2 weighted Fat-suppressed sequences with } \\
\text { motion correction (free breathing with re- } \\
\text { spiratory triggered) for whole thorax in axial } \\
\text { plane) }\end{array}$ & Desirable \\
\hline
\end{tabular}

In patients with active COVID-19 or for those with poor functional status, a short protocol (10-15 min) including a minimum data set of cardiac function and focal myocardial damage (late gadolinium enhancement (LGE)- minimum single shot in short axis (SAx)-orientation) is recommended. In children with active/post COVID-19 a 3D sequence for coronary artery imaging 
to detect eventual coronary dilation/ectasia in proximal or mean segments of the coronary artery tree is recommended. Data acquisition should be as short as possible by using undersampling methods and or reductions in spatial or temporal resolutions without loss of diagnostic image quality. Use of free-breathing and real-time acquisition methods is encouraged. If the patient's functional status allows a scan time of around $30 \mathrm{~min}$, components indicated as "Desirable" in the table should be added to allow advanced tissue characterization and potential assessment of myocardial ischemia. Patients with acute COVID-19 infection often have respiratory compromise in which context risks of vasodilator (regadenoson/adenosine) stress increased: Utility of pharmacolologic stress should be considered on a patient specific basis, considering concomitant risks in the context of active COVID-19 infection. Optional components of the protocol can be added according to the clinical question and patient condition. Parametric mapping imaging acquisition and analysis should follow the SCMR recommendations [18]. Hematocrit should be noted at the time of the CMR exam. Documentation of blood-pressure and heart rate at the time of the CMR scan is recommended.

\section{Scan interpretation and reporting}

When interpreting CMR-exams, SCMR reporting guidelines should be followed [16, 17]. Based on literature published to date, potential findings in COVID-19 patients include acute and chronic myocarditis, pericarditis, left and right heart failure, acute coronary syndromes, myocardial infarction with normal coronary arteries, Kawasaki-like coronary ectasia (expecially in children) and Takotsubo cardiomyopathy. In addition, there may be a high incidence of non-cardiac findings, specifically pulmonary infiltrates or peripheral pulmonary vascular anomalies, in patients with COVID-19. If additional (or still persistent) pulmonary abnormalities are present at CMR-exams, further evaluation should be recommended.

In order to improve understanding of the cardiovascular effects of SARS-CoV-19 infection, SCMR is setting up a global CMR registry with adult (CMR COVID-19) and pediatric sections (CARDOVID study). Clnicians/scientists/researchers involved in reporting CMR scans in COVID-19 patients are encouraged to contribute to this effort. More information at www.scmr.org. Individual cases can be published in the SCMR COVID Case repository at www.scmr.org.

\section{Conclusion}

According to the clinical indication, standard or rapid protocols should be used for COVID-19 patients. Especially short and dedicated CMR examinations that focus on the evaluation of cardiac morphology and function, as well as myocardial tissue characterization are recommended.

\section{Abbreviations}

2Ch: Two-chamber; 3Ch: Three-chamber; 4Ch: Four-chamber;

CMR: Cardiovascular magnetic resonance; COVID-19: Coronavirus disease

2019; DENSE: Displacement encoding with stimulated echoes;

EACVI: European Association of Cardiovascular Imaging; LGE: : Late gadolinium enhancement; MINOCA: Myocardial infarction with nonobstructed coronary arteries; SARS-CoV-2: Severe acute respiratory syndrome coronavirus 2; Sax: Short axis; SCMR: Society for Cardiovascular Magnetic Resonance; fSENC: (fast) Strain encoding; STIR: Short tau inversion recovery

\section{Acknowledgements}

'Not applicable'

Authors' contributions

SK, CBD and SP drafted the manuscript and all authors critically revised the manuscript. The author(s) read and approved the final manuscript.

Funding

Open access funding provided by Projekt DEAL.

Availability of data and materials

'Not applicable'

Ethics approval and consent to participate

'Not applicable'

Consent for publication

'Not applicable'

Competing interests

'Not applicable'

\section{Author details}

${ }^{1}$ DZHK (German Centre for Cardiovascular Research), Berlin, Germany. ${ }^{2}$ German Heart Institute Berlin and Charité University Medicine Berlin, Augustenburger Platz 1, 13353 Berlin, Germany. ${ }^{3}$ Bristol Heart Institute, Bristol NIHR Biomedical Research Centre, University Hospitals Bristol and University of Bristol, Bristol, UK. ${ }^{4}$ Department of Cardiology, Duke University, Durham, North Carolina, USA. ${ }^{5}$ Cardiac Magnetic Resonance Imaging, Cardiovascular Division, Department of Medicine, Brigham and Women's Hospital, Harvard Medical School, 75 Francis Street, Boston, MA 02115, USA. 'Departments of Internal Medicine and Radiology, The Ohio State University, Columbus, OH, USA. ${ }^{7}$ Leeds Institute for Genetics Health and Therapeutics \& Leeds

Multidisciplinary Cardiovascular Research Centre, University of Leeds, Leeds, UK. ${ }^{8}$ Centre de référence "Malformations Cardiaques Congénitales Complexes - M3C" Service de Cardiologie Pédiatrique Hôpital Necker-Enfants Malades, Université Sorbonne Paris Cité, Paris, France. ${ }^{9}$ Department of Medicine, Weill Cornell Medicine, New York, NY, USA. ${ }^{10}$ Heart and Vascular Institute, University of Pittsburgh Medical Center, Pittsburgh, PA, USA. ${ }^{11}$ Department of Radiology, Feinberg School of Medicine, Northwestern University, Chicago, IL, USA.

Received: 1 June 2020 Accepted: 21 July 2020

Published online: 03 September 2020

\section{References}

1. Han Y, Chen T, Bryant J, Bucciarelli-Ducci C, Dyke C, Elliott MD, Ferrari VA, Friedrich MG, Lawton C, Manning WJ, Ordovas K, Plein S, Powell AJ, Raman SV, Carr J. Society for Cardiovascular Magnetic Resonance (SCMR) guidance for the practice of cardiovascular magnetic resonance during the COVID-19 pandemic. J Cardiovasc Magn Reson. 2020;22:26.

2. Babapoor-Farrokhran S, Gill D, Walker J, Rasekhi RT, Bozorgnia B, Amanullah A. Myocardial injury and COVID-19: possible mechanisms. Life Sci. 2020;253: 117723

3. Clerkin KJ, Fried JA, Raikhelkar J, Sayer G, Griffin JM, Masoumi A, Jain SS, Burkhoff D, Kumaraiah D, Rabbani L, Schwartz A, Uriel N. Coronavirus disease 2019 (COVID-19) and cardiovascular disease. Circulation. 2020;141(20):1648-55. 
4. Fried JA, Ramasubbu K, Bhatt R, Topkara VK, Clerkin KJ, Horn E, Rabbani L, Brodie D, Jain SS, Kirtane A, Masoumi A, Takeda K, Kumaraiah D, Burkhoff D, Leon M, Schwartz A, Uriel N, Sayer G. The variety of cardiovascular presentations of COVID-19. Circulation. 2020;141(23):1930-6.

5. Inciardi RM, Adamo M, Lupi L, Cani DS, Di Pasquale M, Tomasoni D, Italia L, Zaccone G, Tedino C, Fabbricatore D, Curnis A, Faggiano P, Gorga E, Lombardi CM, Milesi G, Vizzardi E, Volpini M, Nodari S, Specchia C, Maroldi R, Bezzi M, Metra M. Characteristics and outcomes of patients hospitalized for COVID-19 and cardiac disease in northern Italy. Eur Heart J. 2020;41(19): $1821-9$.

6. Shi S, Qin M, Shen B, Cai Y, Liu T, Yang F, Gong W, Liu X, Liang J, Zhao Q, Huang H, Yang B, Huang C. Association of cardiac injury with mortality in hospitalized patients with COVID-19 in Wuhan, China. JAMA Cardiol. 2020; 5(7):802-10

7. Stefanini GG, Montorfano M, Trabattoni D, Andreini D, Ferrante G, Ancona M, Metra M, Curello S, Maffeo D, Pero G, Cacucci M, Assanelli E, Bellini B, Russo F, lelasi A, Tespili M, Danzi GB, Vandoni P, Bollati M, Barbieri L, Oreglia J, Lettieri C, Cremonesi A, Carugo S, Reimers B, Condorelli G, Chieffo A. ST-elevation myocardial infarction in patients with COVID-19: clinical and angiographic outcomes. Circulation. 2020;141(25):2113-6.

8. Zheng YY, Ma YT, Zhang JY, Xie X. COVID-19 and the cardiovascular system. Nat Rev Cardiol. 2020;17:259-60.

9. Xiong TY, Redwood S, Prendergast B, Chen M. Coronaviruses and the cardiovascular system: acute and long-term implications. Eur Heart J. 2020; 41(19):1798-800.

10. Kwong RY, Petersen SE, Schulz-Menger J, Arai AE, Bingham SE, Chen Y, Choi YL Cury RC, Ferreira VM, Flamm SD, Steel K, Bandettini WP, Martin ET, Nallamshetty L, Neubauer S, Raman SV, Schelbert EB, Valeti US, Cao JJ, Reichek N, Young AA, Fexon L, Pivovarov M, Ferrari VA, Simonetti OP. The global cardiovascular magnetic resonance registry (GCMR) of the society for cardiovascular magnetic resonance (SCMR): its goals, rationale, data infrastructure, and current developments. J Cardiovasc Magn Reson. 2017;19:23.

11. von Knobelsdorff-Brenkenhoff F, Pilz G, Schulz-Menger J. Representation of cardiovascular magnetic resonance in the AHA / ACC guidelines. J Cardiovasc Magn Reson. 2017:19:70

12. von Knobelsdorff-Brenkenhoff F, Schulz-Menger J. Role of cardiovascular magnetic resonance in the guidelines of the European Society of Cardiology. J Cardiovasc Magn Reson. 2016;18:6.

13. Verdoni L, Mazza A, Gervasoni A, Martelli L, Ruggeri M, Ciuffreda M, Bonanomi E, D'Antiga L. An outbreak of severe Kawasaki-like disease at the Italian epicentre of the SARS-CoV-2 epidemic: an observational cohort study. Lancet. 2020;395(10239):1771-8.

14. Viner RM, Whittaker E. Kawasaki-like disease: emerging complication during the COVID-19 pandemic. Lancet. 2020;395(10239):1741-3.

15. Skulstad H, Cosyns B, Popescu BA, Galderisi M, Salvo GD, Donal E, Petersen S, Gimelli A, Haugaa KH, Muraru D, Almeida AG, Schulz-Menger J, Dweck MR, Pontone G, Sade LE, Gerber B, Maurovich-Horvat P, Bharucha T, Cameli M, Magne J, Westwood M, Maurer G, Edvardsen T. COVID-19 pandemic and cardiac imaging: EACVI recommendations on precautions, indications, prioritization, and protection for patients and healthcare personnel. Eur Heart J Cardiovasc Imaging. 2020;21(6):592-8.

16. Schulz-Menger J, Bluemke DA, Bremerich J, Flamm SD, Fogel MA, Friedrich MG, Kim RJ, von Knobelsdorff-Brenkenhoff F, Kramer CM, Pennell DJ, Plein S, Nagel E. Standardized image interpretation and post-processing in cardiovascular magnetic resonance - 2020 update: Society for Cardiovascular Magnetic Resonance (SCMR): Board of Trustees Task Force on Standardized Post-Processing. J Cardiovasc Magn Reson. 2020;22:19.

17. Kramer CM, Barkhausen J, Bucciarelli-Ducci C, Flamm SD, Kim RJ, Nagel E. Standardized cardiovascular magnetic resonance imaging (CMR) protocols: 2020 update. J Cardiovasc Magn Reson. 2020;22:17.

18. Messroghli DR, Moon JC, Ferreira VM, Grosse-Wortmann L, He T, Kellman P, Mascherbauer J, Nezafat R, Salerno M, Schelbert EB, Taylor AJ, Thompson R, Ugander M, van Heeswijk RB, Friedrich MG. Clinical recommendations for cardiovascular magnetic resonance mapping of $\mathrm{T} 1, \mathrm{~T}_{2}, \mathrm{~T}^{*}$ and extracellular volume: A consensus statement by the Society for Cardiovascular Magnetic Resonance (SCMR) endorsed by the European Association for Cardiovascular Imaging (EACVI). J Cardiovasc Magn Reson. 2017;19(1):75.

\section{Publisher's Note}

Springer Nature remains neutral with regard to jurisdictional claims in published maps and institutional affiliations.

\section{Ready to submit your research? Choose BMC and benefit from}

- fast, convenient online submission

- thorough peer review by experienced researchers in your field

- rapid publication on acceptance

- support for research data, including large and complex data types

- gold Open Access which fosters wider collaboration and increased citations

- maximum visibility for your research: over $100 \mathrm{M}$ website views per year

At BMC, research is always in progress.

Learn more biomedcentral.com/submissions 